\title{
PENGARUH KELEKATAN ORANG TUA DAN ANAK TERHADAP PENGGUNAAN TEKNOLOGI DIGITAL ANAK USIA DINI
}

\author{
Irfan Fauzi Rachmat \\ irfanfrachmat@gmail.com \\ Universitas Muhammadiyah Cirebon
}

\begin{abstract}
Kebiasaan anak menggunakan gadget, saat ini sudah semakin mudah ditemukan di manapun. Baik itu saat anak di rumah, di lingkungan bermain, di tempat umum atau tempat-tempat lainnya. Anak terlalu asyik dan lupa terhadap lingkungan disekitanya ketika sedang berinteraksi dengan gadget. Anak yang seharusnya melakukan aktivitas bermain yang sesuai dengan usianya, malah sibuk dan tersihir melalui serunya bermain games, atau sekadar menonton video-video di Youtube. Akibat yang ditimbulkan dari kebiasaan berlama-lama menggunakan gadget adalah seperti terganggunya fungsi eksekutif anak, kurang fokus, minim kreativitas, dan gangguan kesehatan lainnya seperti radiasi mata, dan obesitas.

Fenomena tersebut harus dipahami dan diketahui oleh para orang tua atau pengasuh. Orang tua agar senantiasa waspada terhadap penggunaan gadget anak yang semakin tidak terkendali. Oleh karena itu, penelitian ini membahas tentang pola kelekatan, lingkungan belajar di rumah dan cara berkomunikasi interpersonal antara orang tua dan anak. Variabel tersebut dikaji dan ditelusuri melalui studi literature dari beberapa jurnal yang relevan. Metode penelitian menggunakan pendekatan studi literature, dengan me review sejumlah 26 jurnal yang terkait dengan variabel penelitian. Jurnal tersebut di ambil dari beberapa tahun terakhir, dan terbaru.

Studi literature review ini memberikan implikasi pada pola asuh yang dalam hal ini lebih spesifik pada kelekatan anak. Orang tua diharapkan dapat membangun kelekatan yang positif dengan anak. Kelekatan anak akan terjadi apabila orang tua banyak melakukan aktivitas bersama dengan anak. Bermain fisik secara bersama, berdialog atau berkomunikasi bersama, atau menemani anak saat menggunakan perangkat digital. Hasilnya adalah, kebiasaan menggunakan perangkat digital memang salah satu penyebab yang memicu nya adalah karena lemahnya peran komunikasi interpersonal dari orang tua, ditambah dengan penyediaan ragam bermain dan belajar di rumah yang minim. Selain itu pula, kelekatan yang dibangun pun merupakan penyebab yang paling besar mempengaruhi nya.
\end{abstract}

Kata Kunci : kelekatan, literasi digital, tekonologi digital. 


\section{PENDAHULUAN}

Anak usia dini tumbuh dan berkembang di dalam lingkungan yang beragam. Dari mulai lingkungan makro, meso maupun mikro (Santrock, 2017). Salah satu lingkungan yang paling dekat dengan anak adalah lingkungan keluarga. Lingkungan keluarga akan sangat mempengaruhi perkembangan anak usia dini. Orang tua yang men setting lingkungan keluarga akan secara langsung mempengaruhi perkembangan anak. Orang tua lah aktor utama bagaimana anak usia dini bertumbuh dan berkembang (Riza, 2016).

Menurut Bandura (1991) perkembangan seorang anak tidak hanya di pengaruhi oleh lingkungan keluarga saja, namun juga sangat di pengaruhi oleh lingkungan sekitar dan orang-orang yang ada di sekitarnya (Hardani, 2017). Karena lingkungan keluarga merupakan lingkungan terdekat dan pertama bagi anak dalam mempersiapkan anak untuk memasuki lingkungan sosial berikutnya (Hardani, 2017). Sehingga sebagai orang tua, sudah seharusnya lah untuk mendukung ragam lingkungan yang baik untuk anak, agar tidak ter dampak kedalam hal negatif akibat dari zaman yang cepat berubah.

Kemajuan zaman yang terjadi dewasa ini telah berkembang sangat cepat. Tentu hal ini akan sangat mempengaruhi lingkungan dimana anak bermain dan belajar. Zaman Internet, atau dikenal dengan istilah IOT (Internet of Things) telah menjadi kebutuhan dan gaya hidup sehari hari. Dikenal sebagai revolusi industri 4.0, yang menekankan pada Artificial Intelligence, Big Data, Robotics dan lainnya. Penggunaan perangkat digital dan kecanggihan teknologi tersebut tidak hanya digunakan di dalam perusahaan atau sekolah-sekolah, namun telah masuk kedalam lingkungan keluarga.

Akses informasi sangat mudah di dapatkan. Hanya dengan menggunakan smartphone, dapat menemukan beragam informasi data yang di ingin kan. Baik dari segi berita, jual beli, social media, dan hiburan dapat dengan mudah di dapatkan. Salah satu pengguna terbesar teknologi tersebut adalah diantaranya adalah para orang tua, khususnya orang tua yang memiliki anak usia dini.

Orang tua sebagai orang yang pertama dan utama dalam mendidik anak, memiliki peran yang begitu strategis dalam setiap aspek perkembangan anak. Orang tua yang memahami kemajuan teknologi dengan bijak, akan memanfaatkan kemajuan internet dan lainnya itu sebagai sarana untuk pembelajaran kepada anaknya. Namun ada juga orang tua yang menggunakan pesatnya teknologi hanya untuk kebutuhan yang kurang begitu bermanfaat. Perilaku orang tua dalam menggunakan perangkat Teknologi digital ini akan mempengaruhi interaksi antara orang tua dan anak.

Orang tua dengan penggunaan telepon seluler di depan anak, akan mengurangi interaksi orang tua dan anak (Kildare \& Middlemiss, 2017). Kualitas hubungan orang tua dan anak akan rendah, baik secara aktivitas komunikasi verbal, maupun nonverbal (Kildare \& Middlemiss, 
2017). Perilaku orang tua yang memiliki durasi waktu layar tinggi akan mempengaruhi tingginya waktu layar anak juga (Lauricella, Wartella, \& Rideout, 2015). Artinya bahwa semakin tinggi tingkat penggunaan TV oleh orang tua, maka semakin tinggi pula waktu anak untuk menonton TV. Terlebih adalah seorang ibu, waktu menonton yang dilakukan oleh Ibu adalah lebih kuat untuk anak menjadi lebih tinggi waktu menontonnya, daripada waktu menonton ayah (Jago et al., 2012).

Kemudian, orang tua kerap memberikan ragam fasilitas Teknologi digital, dengan anggapan agar anak nya tidak ketinggalan zaman. Anak dibiarkan memiliki dan mengakses perangkat Teknologi digital dengan alasan agar anak tidak banyak mengganggu aktivitas ayah ibu nya. Sikap orang tua acuh dan tidak menerapkan aturan yang ketat dalam penggunaan Teknologi digital untuk anak usia dini kerap menjadi penyebab muncul nya ragam masalah yang terjadi pada diri anak.

\section{Dampak}

penggunaan

Teknologi digital bagi kesehatan anak seringkali muncul apabila menggunakan nya secara berlebihan. Seperti kesehatan mata akan mengalami kelelahan (Goh, Bay, \& Chen, 2015). Paparan dari radiasi Teknologi digital sangat berbahaya bagi kesehatan dan perkembangan anak. Beresiko tinggi mengakibatkan gangguan terhadap sistem imun atau kekebalan tubuh (Musthafa, 2017). Hal ini disebabkan anak yang kecanduan Teknologi digital akan malas bergerak sehingga terjadi penumpukan lemak yang pada akhirnya menyebabkan obesita (Mariskhana, 2017)s pada anak.
Dampak kesehatan lainnya pun bisa mempengaruhi kesehatan penglihatan dan pendengaran anak (Musthafa, 2017).

Bagi perkembangan otak pun akan berdampak pada rendahnya prestasi belajar siswa (Mariskhana, 2017). Anak-anak akan lupa akan waktu, lebih memilih berlama-lama menggunakan Teknologi digital dibandingkan menyiapkan untuk belajar. Hal ini dipertegas oleh badan kesehatan dunia WHO yang memberikan perhatian serius terhadap pengaruh penggunaan paparan radiasi ponsel. Dikenal dengan RF (radiofrequency) memberikan peluang bagi para pengguna ponsel untuk terkena kanker (Repacholi, 2001). Diperkuat dengan temuan dalam penelitian yang dilakukan oleh Hardel MD dalam (Khurana, Teo, Kundi, Hardell, \& Carlberg, 2009), menyatakan bahwa menggunakan ponsel lebih dari atau selama 10 tahun akan mengalami dua kali lipat risiko terkena tumor otak.

Berlebihan nya anak menggunakan telephone selular untuk melihat beragam konten di layar, akan mempengaruhi terhadap kontrol diri dan emosional anak. Anak yang menghabiskan waktunya dengan Teknologi digital akan lebih emosional, pemberontak karena tidak ingin waktu bermain nya di ganggu (Chusna, 2017). Anak menjadi mudah marah, melawan orang tua, dan sikap aggressive lainnya. Hal ini berdampak pada karakter anak yang kurang dapat mengontrol diri.

Beragam masalah diatas, tentu salah satu penyebab nya adalah berasal dari pola asuh yang diterapkan oleh orang tua. Kebiasaan orang tua dalam menggunakan 
beragam perangkat digital, dapat secara langsung mempengaruhi kebiasaan anak pula. Menurut Bowlby (1969) menjelaskan bahwa durasi penggunaan Teknologi digital sangat berpengaruh terhadap kebiasaan anak menjadi kecanduan Teknologi digital (J. Bowlby, 1969). Tingginya interaksi orang tua dengan Teknologi digital dapat mempengaruhi kualitas interaksi orang tua dengan anak (Kildare \& Middlemiss, 2017).

Orang tua yang terlalu asyik dengan perangkat gawai pintar nya akan mengurangi kelekatan dengan anak. Orang tua akan mengabaikan anak pada saat sekadar mengecek pesan singkat atau social media. Akibatnya anak merasa di acuhkan, dan merasa tidak terjadi bonding yang diharapkan oleh anak. Sehingga anak akan belajar dan meniru apa yang orang tua perlihatkan pada saat berinteraksi dengan Teknologi digital nya.

Tinggi nya anak menggunakan perangkat digital pun salah satu penyebabnya adalah rendahnya aturan yang diberikan oleh orang tua. Banyak orang tua yang memberikan Teknologi digital kepada anaknya dengan alasan agar anaknya diam, tenang, tidak mengganggu aktivitas orang tuanya. Atau dengan alasan, orang tua memberikan Teknologi digital kepada anaknya agar anak tidak tertinggal dengan teman-teman nya, yang sudah menggunakan Teknologi digital, dan merasa itu tidak memiliki dampak apapun. Sehingga akan berdampak pada kualitas kelekatan orang tua dan anak.

Dari pemaparan diatas, maka peneliti tertarik untuk mengkaji lebih dalam tentang pengaruh kelekatan terhadap perilaku penggunaan Teknologi digital anak usia dini. Diharapkan dari penelitian ini di dapatkan satu kesimpulan yang menjelaskan tentang penyebab utama terhadap perilaku penggunaan Teknologi digital anak. Sehingga menjadi saran kepada para orang tua pada khususnya dan pemangku kebijakan pada umumnya, untuk meningkatkan kualitas kelekatan antara orang tua dan anak.

\section{KAJIAN PUSTAKA}

\section{Definisi Kelekatan}

Kelekatan adalah ikatan psikologis dan emosional yang terjadi antara pengasuh atau ibu dengan anak, yang ditandai dengan cemas ketika berpisah, senang atau gembira ketika figur lekatnya kembali, dan memiliki orientasi tetap pada figur lekat walaupun tidak melakukan interaksi atau tatap muka (Holmes, 2014)

"Attachment is a 'primary motivational system' with its own workings and interface with other motivational systems." (John Bowlby, 1969) dalam (Holmes, 2014)

Sistem kelekatan yang terjadi antara ibu dan anak ini menurut Bowlby dikenal dengan istilah Internal Working memory. Dimulai pada saat proses pemberian ASI (air susu ibu) Melalui proses pemberian ASI diharapkan akan berkembang kelekatan dan tingkah laku lekat karena dalam proses ini terjadi kontak fisik yang disertai upaya untuk membangun hubungan psikologis antara ibu dan anak (Ervika, 2005)

Konsep working model selanjutnya dikembangkan oleh 
Collins dan Read (Collins \& Read, 1994) yang terdiri dari empat komponen yang saling berhubungan, yaitu; 1) Memori tentang kelekatan yang dihubungkan dengan pengalaman; 2) Kepercayaan, sikap dan harapan mengenai diri dan orang lain yang dihubungkan dengan kelekatan; 3) Kelekatan dihubungkan dengan tujuan dan kebutuhan (goal and needs); 4) Strategi dan rencana yang diasosiasikan dengan pencapaian tujuan kelekatan.

\section{Definisi Perilaku Penggunaan Teknologi digital}

Teknologi digital adalah seperangkat alat yang memiliki fungsi tertentu, yang dapat bermanfaat untuk kehidupan manusia, baik untuk segi bisnis, akses informasi, hiburan dan lain sebagainya.

Sedangkan perilaku penggunaan Teknologi digital adalah seperangkat kemampuan anak usia dini dalam mengakses, menyimpan, mengirim, dan memanipulasi informasi melalui format digital. Seperti saat anak menggunakan perangkat digital (smartphone, kamera, TV, laptop, dan games console) sehingga menghasilkan sebuah suara, gambar atau video yang ter koneksi dengan internet ataupun tidak.

Penggunaan perangkat digital anak usia dini adalah perilaku yang terjadi pada anak usia dini dalam menggunakan perangkat digital, seperti penggunaan smartphone, ponsel, TV, dan lainnya. Perilaku ini telah sering banyak di jumpai di masyarakat, baik di lingkungan keluarga atau sekolah.

\section{Dampak penggunaan Teknologi digital:}

Penggunaan perangkat digital secara berlebihan akan berdampak buruk pada perkembangan anak. Anak yang menggunakan perangkat digital secara berlebihan akan lebih emosional, pemberontak dan merasa terganggu apabila orang tua mengambil atau menghentikan aktivitas dengan perangkat digital nya (Chusna, 2017).

Anak di anggap sudah kebablasan dalam bermain Teknologi digital apabila dalam satu hari bermain dengan perangkat itu lebih dari 2 jam sehari (Febrino, 2017), sehingga akan berdampak pada anak yang tantrum, menangis berlebihan atau berteriak-teriak. Tentu hal ini berdampak pada hubungan kelekatan antara orang tua dan anak.

Dampak Teknologi digital lainnya adalah anak akan mengalami penurunan kemampuan bersosialisasi dengan baik. Menjadi tidak peduli terhadap lingkungan sekitar, menjadi acuh terhadap ajakan temannya (Febrino, 2017). Anak seolah asyik dan menikmati kesendirian dan tidak peduli dengan teman lainnya.

Menurut Sihura (2018) dampak penggunaan perangkat digital bagi anak usia dini adalah sebagai berikut (Sihura, 2018) :

1. Emosional anak yang tidak terkontrol

2. Beresiko terhadap bahaya radiasi.

3. Leher menjadi sakit, dan merubah struktur anatomi tubuh.

4. Menghambat perkembangan anak.

5. Perubahan perilaku anak menjadi perilaku yang bermasalah. 


\section{METODE}

\section{Literature Review.}

Metode yang digunakan adalah literature review, atau kajian sumber pustaka. Metode ini digunakan untuk mendapatkan informasi dan kekuatan sumber ilmiah sebelum peneliti melakukan penelitian di lapangan. Sehingga di harapkan dari literature review ini di dapatkan beragam teori dan penemuan ilmiah yang berkaitan dengan masalah yang ditemukan, yang pada akhirnya dapat membentuk sebuah kerangka berfikir ilmiah.

Adapun kajian sumber referensi dalam jurnal ini adalah diambil dari jurnal-jurnal relevan dengan masalah yang dikemukakan diatas. Terdapat 24 jurnal yang sesuai dengan permasalahan dan topik pengaruh kelekatan terhadap penggunaan Teknologi digital anak usia dini. Jurnal tersebut di dapatkan dari sumber online secara open access. Dikumpulkan dan ditelaah berdasarkan urutan tahun terbit. Poin yang menjadi bahan review adalah poin judul penelitian, masalah penelitian, jenis penelitian, hasil, dan saran atau implikasi nya. Adapun lebih detail Adapun jurnal yang berhubungan dengan kelekatan dan penggunaan Teknologi digital adalah sebagai berikut :

No Judul dan Penulis Hasil dan Implikasi

1. Waktu menonton anak usia dini : Penggunaan waktu layar orang tua sangat peran kompleks dari faktor orang mempengaruhi waktu layar anak. Anak usia 0-8 tua dan anak tahun menghabiskan empat perangkat digital, televisi, komputer, smartphone dan tablet.

(Lauricella et al., 2015)

2. Dampak penggunaan perangkat seluler orang tua terhadap interaksi orang tua dan anak.

(Kildare \& Middlemiss, 2017)
Orang tua yang menggunakan Teknologi digital selama ber interaksi dengan anak akan menggangu kualitas hubungan interaksi orang tua dan anak. Anak akan mencari perhatian orang tua nya dengan cara cara yag beresiko mencederai anak.

3. Efek paparan televisi pada Anak usia dini menonton TV rata rata setiap keterampilan perkembangan anak harinya sebesar 67,4 menit sebelum usia 2 usia dini.

(Lin, Cherng, Chen, Chen, \& Yang, 2015) tahun. Menonton TV akan meningkatkan resiko keterlambatan kognitif, bahasa, dan motorik pada anak. Orang tua yang membiarkan anak nya untuk menonton TV secara berlebihan akan dapat merugikan perkembangan anak. 
Hasil dan Implikasi

4. Hubungan antara gaya pengasuhan melalui penggunaan media dengan waktu laya (screen time) anak anak di Libanon.

(Samaha \& Hawi, 2017)
Anak usia dini yang mendapatkan perilaku yang baik dari orang tua, menghargai prestasi anaknya, menghukum anak dengan mengurangi waktu menonton, akan memberikan dampak pada anak usia dini untuk menonton kurang dari 2 jam sehari. Implikasi nya adalah

5. Hubungan antara Paparan televisi, Temuan penelitian menunjukkan hubungan Kognitif anak, dan perilaku anak : antara menonton TV dengan perkembangan Sebuah Tinjauan Sistematis. anak secara kompleks. Pengaruh paparan TV akan bergantung pada karakteristik anak, (Kostyrka-Allchorne, Cooper, \& lingkungan keluarga, dan juga konteks sosial. Simpson, 2017) Sebaiknya menghindari anak bayi terpapar TV sejak dini.

6. Persepsi Orang tua tentang Teknologi dan pengasuhan yang berfokus pada teknologi: hubungan dengan waktu layar (Screen time) anak usia dini.

(Ihmeideh \& Alkhawaldeh, 2017)
Menemukan model pengasuhan, waktu layar anak, dan dampak psikopatologi anak. Memeriksa tiga tahapan perkembangan anak, yaitu masa kanak kaak, masa kecil menengah, dan remaja. Persepsi orang tua dalam mengasuh anak, sangat efektif dengan menggunakan teknologi, hal ini terkait dengan strategi pengasuhan yang dilakukan. Seiring bertambahnya usia anak, efektivitas teknologi dalam pengasuhan anak akan berkurang dan justru akan menimbulkan perilaku bermasalah.

7. Faktor yang mempengaruhi Faktor sikap dan karakter anak memiliki efek penggunaan Teknologi digital pada langsung terkuat pada penggunaan Teknologi pendidikan anak usia dini

(Blackwell, Lauricella, \& Wartella, 2014) pun memiliki pengaruh yang paling kuat terhadap sikap anak dalam menggunakan Teknologi digital. Orang tua yang memahami tentang literasi digital dan pengalaman akan mempengaruhi penggunaan Teknologi digital anak usia dini.

8. Pembelajaran anak Prasekolah Mengidntifikasi anak anak pra sekolah dalam 14 dengan menggunakan teknologi di rumah. bentuk utama dalam pembelajaran dengan teknologi dalam kehidupan sehari hari yang 
Hasil dan Implikasi

sering diabaikan. Bentuk pengabaian tersebut akan berdampak pada anak tidak memiliki

(Plowman, Stevenson, Stephen, \& keterampilan operasional, memperluas McPake, 2012) pengetahuan dan pemahaman dunia, mengembangkan diri dalam hal belajar. Hal ini terjadi karena pengaruh dari praktek yang dilakukan oleh orang tua serta sikap orang tua.

9. Pengaruh menonton TV pada Penelitian ini menghasilkan temuan bahwa bahasa ibu terhadap anak balita.

(Lavigne, Hanson, \& Anderson, 2015)

10. Waktu tampilan layar orang tua dan anak terhadap ragam media yang ada di lingkungan rumah.

(Jago et al., 2012)

Waktu menonton TV orang tua sangat mempengaruhi waktu menonton TV anak di hari kerja dan akhir pekan di seluruh kelompok usia dan kelompok jenis kelamin. Waktu menonton ibu adalah prediktor terkuat dari pada waktu menonton ayah terhadap waktu menonton anak. Anak menggunakan peralatan permainan elektronik di rumah dapat meningkatkan kemungkinan bahwa anak akan menghabiskan 1 jam menggunakan gabungan media lain pada hari kerja dan akhir pekan.

11. Waktu layar dan tidur di antara anak usia sekolah dan remaha: sebuah tinjauan literature sistematis.

Menemukan hampir 90\% literatur yang menyatakan bahwa waktu layar sangat berdampak buruk pada waktu tidur.

(Hale \& Guan, 2015)

12. Penggunaan media elektronik dan

Banyak variabel yang di teliti dalam studi ini, tidur pada anak usia sekolah dan remaja: sebuah ulasan.

(Cain \& Gradisar, 2010) menyatakan bahwa waktu tidur yang tertunda, dan waktu tidur total yang lebih pendek sebagai akibat dari penggunaan media elektronik. Media elektronik dalam penelitian ini meliputi :

13. Penggunaan media Tablet layar Memeriksan penggunaan tablet di pra sekolah sentuh untuk menulis dan membaca terhadap kemampuan keaksaraan yang muncul. Hasil penelitian menemukan bahwa terdapat 
No Judul dan Penulis anak usia dini di rumah : hubungan dengan munculnya keaksaraan.

(Neumann, 2016)
Hasil dan Implikasi

hubungan yang positif antara penggunaan Tablet (mengakses aplikasi di dalamnya) terhadap kemampuan pengetahuan bacaan teks. Terdapat hubungan positif ditemukan antara menulis dengan tablet dan kemampuan aksara dan membaca.

14. Intervensi Teknologi dalam pengasuhan anak anak: Implikasi untuk persepsi ibu tentang pengasuhan.

(McDaniel \& Coyne, 2016)
Banyak ibu menganggap bahwa teknologi dapat menggangu interaksi pengasuhan antara ibu dengan anak pada setiap kesempatan, terutama saat waktu bermain dengan anak. Banyak ibu yang melaporkan bahwa banyak nya gangguan, pengasuhan yang buruk, depresi, ftustasi. Saran dari penelitian ini adalah setiap ibu untuk memeriksa secara kritis terhadap penggunaan teknologi selama ber interaksi dengan keluarga.

Perilaku hiperaktif anak yang berusia 4 tahun dikaitkan dengan peningkatan menonton TV. Pengaruh menonton TV anak dan ditambah dengan status ekonomi sosial orang tua yang rendah dan orang tua perempuan (ibu) dapat memberikan efek kuat lainnya terhadap hiperaktif anak.

16. Hubungan menonton TV, Hasilnya menunjukkan hubungan positif yang penggunaan komputer, dan signifikan (untuk penggunaan komputer dan membaca terhadap fungsi-fungsi membaca) dan negatif (untuk menonton TV) neurocognitive anak-anak

(Rosenqvist, Lahti-Nuuttila, antara penggunaan media dan fungsi neurocognitive sebagaimana dinilai oleh NEPSY-II. Menggunakan komputer berhubungan positif dengan perhatian dan fungsi eksekutif. Ditemukan hubungan yang positif antara kemampuan membaca dan kemampuan neurokognisi pada anak. Di tambah Holdnack, Kemp, \& Laasonen, dengan tingkat pendidikan ibu yang rendah, 2016) maka sebagai predictor yang kuat terhadap neurocognitive anak.

17. Kerangka panduan untuk Semakin meningkatnya data di lapangan tentang mempertimbangkan layar sentuh penggunaan perangkat digital untuk balita pada anak di bawah usia 2 tahun. (dibawah 2 tahun). American pediatrics tidak menemukan cukup bukti tentang manfaat perangkat digital untuk anak balita dibawah 2 tahun. Jurnal ini menelaah tentang tinjauan 
Hasil dan Implikasi

naratif tentang rekomendasi penggunaan layar

(Kucirkova \& Zuckerman, 2017) sentuh di bawah 2 tahun. Sehingga diharapkan akan terbentuk kerangka panduan untuk orang tua.

18. Faktor-faktor yang terkait dengan perubahan waktu layar balita dalam Studi STEPS: Tindak lanjut dua tahun

(Matarma, Koski, Löyttyniemi, \& Lagström, 2016)
Waktu menonton balita meningkat rata-rata 55 menit dari 1 hingga 3 tahun. Anak-anak dengan orang tua yang berpendidikan lebih tinggi memiliki peningkatan yang lebih kecil dalam waktu layar.

Waktu layar ibu yang lebih tinggi memiliki efek pada peningkatan waktu layar yang lebih besar pada balita. Anak-anak yang menghadiri penitipan anak-anak memiliki peningkatan waktu layar yang lebih kecil. Aktivitas fisik orang tua tidak berpengaruh pada perubahan waktu layar balita.

Meneliti tentang konten program dan konteks budaya yang di tampilkan televisi pada kompetensi sosial emosional anak. Hubungan antara durasi menonton dan risiko SEC adalah kuadrat daripada linier.

(Chongsuvivatwong,

Ruangdaraganon, Intusoma, Mosuwan, \& Panyayong, 2013)

20. Mereka bisa berinteraksi, tetapi bisakah mereka belajar? Transfer pembelajaran balita dari layar sentuh dan televisi.
Penelitian ini membahas tentang perilaku imitasi yang dilakukan oleh balita terhadap layar TV. Mentransfer pembelajaran dari layar sentuh lebih mudah dilakukan daripada dari video TV.

(Moser et al., 2015)

21. Anak usia dini menggunakan perangkat digital dan aturan orang tua.

(Goh et al., 2015)
Menemukan hasil penelitian bahwa anak anak secara sukarela menyetujui aturan orang tua nya dalam menggunakan perangkat digital. Aturan orang tua dalam membatasi anak menggunakan perangkat digital adalah aturan batasan waktu. Bermain game adalah kegiatan yang paling banyak dilakukan anak dalam menggunakan perangkat digital, dibandingkan dengan lainnya. 
22. Dampak dari video yang diarahkan kepada bayi dan interaksi nya dengan orang tua

(Kirkorian, Anderson, Demers, Pempek, \& Hanson, 2010)
Orang tua mengawasi anak nya saat diputarkan video sesame and street. Interaksi dengan orang tua terasa lebih besar setelah menonton Sesame Beginings. Orang tua menggunakan konten video sebagai dasar untuk berinteraksi dengan bayinya. Interaksi orang tua dan anak akan menurun secara kuantitas maupun kualitas saat video diputar.

Rata-rata, anak-anak dalam penelitian ini terpapar 4, 1 jam waktu layar setiap hari, termasuk 3, 6 jam di rumah dan 0, 4 jam di penitipan anak. Anak-anak di pusat memiliki waktu layar terendah (3, 2 jam) dibandingkan dengan anak-anak dalam perawatan orang tua (Tandon, Zhou, Lozano, \& saja (4, 4 jam).
24. Media layar dan perkembangan bahasa pada bayi dan balita: sebuah perspektif ekologis.

(Linebarger \& Vaala, 2010)
Selama dekade terakhir, konten media layar yang ditujukan pada bayi dan balita meningkat secara dramatis. Akibatnya, waktu bayi dan balita yang dihabiskan dengan media juga meningkat (yaitu, 1-2 h per hari). Efek media layar tergantung pada sejauh mana konten media menyerupai pengalaman kehidupan nyata bayi dan balita termasuk penggunaan cerita sederhana dan objek atau rutinitas yang akrab. 


\section{HASIL DAN DISKUSI}

Dari ke 24 jurnal tersebut, didapatkan hasil bahwa penggunaan teknologi anak usia dini memiliki dampak negatif maupun positif. Beberapa jurnal membahas tentang pengaruh negatif penggunaan Teknologi digital sejak dini, seperti masalah kualitas tidur anak, hubungan sosial emosional anak, kognitif anak, speech delay, dan pengaruh terhadap aspek neurologis anak.

Terdapat beragam jurnal yang membahas tentang kelekatan anak yang terganggu akibat dari interaksi orang tua dengan perangka digital nya. Kemudian, tingginya paparan Teknologi digital dipengaruhi oleh status ekonomi sosial, serta tingkat pendidikan orang tua, khususnya ibu.

Pengasuhan yang dilakukan orang tua kepada anak, seiring nya berkembangnya perkembangan teknologi, menyebabkan pola pengasuhan yang ter ganggu (distraction). Pengasuhan, baik dari segi kualitas dan kuantitas akan rendah, hal ini disebabkan terganggu nya fokus dan perhatian anak dalam mengasuh anak. Imbasnya, anak akan mengikuti apa yang orang tua lakukan.

Bentuk imitasi anak terhadap penggunaan Teknologi digital yaitu berupa peniruan penggunaan perangkat digital, baik berupa kuantitas (waktu layar anak) ataupun kualitas konten yang di akses oleh anak.

Hubungan kelekatan orang tua dan penggunaan Teknologi digital anak.

Dampak negatif penggunaan Teknologi digital terhadap anak merupakan akibat yang ditimbulkan dari interaksi orang tua dan anak di lingkungan keluarga. Orang tua yang terlibat aktif dengan anak, seperti bermain bersama, bercerita, dan melakukan aktivitas bersama (tanpa terganggu dengan Teknologi digital) akan meningkatkan hubungan kelekatan antara orang tua dan anak.

Kelekatan antara orang tua dan anak, akan terjadi apabila orang tua memberikan bentuk perhatian dan respons yang positif kepada anak. Orang tua menjadi sahabat bagi anak, anak akan merasa nyaman apabila selalu dekat dengan orang tua. Sebaliknya, apabila anak tidak mendapatkan perhatian dan waktu khusus terlibat aktivitas dengan orang tua nya, maka salah satu aktivitas yang dilakukan anak adalah dengan bermain sendiri, dan salah satu bentuk pelarian bermain sendiri nya adalah dengan sibuk bermain Teknologi digital dengan intensitas waktu yang lama.

\section{KESIMPULAN DAN SARAN}

Penggunaan perangkat digital, seperti smartphone, console games, dan TV merupakan suatu kebiasaan yang mudah ditemukan di lingkungan rumah anak. Anak mudah dalam mengakses beragam perangkat tersebut, sehingga akan berdampak pada pertumbuhan dan perkembangan anak, baik secara positif maupun negatif.

Untuk mengurangi dampak negatif yang terjadi pada anak, maka diperlukan suatu kesadaran atau literasi digital untuk orang tua. Orang tua harus memberikan peran sebagai figure yang selalu mendampingi anak ketika anak ber interaksi dengan 
perangkat digital. Sehingga dari kegiatan mendampingi anak tersebut, akan muncul hubungan kelekatan yang aman bagi anak, dengan cara berkomunikasi dan menjelaskan tentang tayangan-tayangan yang ada di TV atau interaksi anak dengan smartphone.

Hubungan kelekatan yang aman (secure attachment) akan berdampak pada perilaku anak pada saat menggunakan perangkat digital. Anak yang memiliki hubungan kelekatan yang baik dengan anak, akan memiliki kemampuan literasi digital yang baik, dibandingkan anak yang diberikan kebebasan (tidak mendapatkan perhatian penuh) dari orang tua nya. Contoh kemampuan literasi digital anak misalnya anak akan meminta izin kepada orang tua nya saat hendak menyalakan atau menggunakan perangkat digital. Anak akan memilih konten-konten yang sesuai dengan umur nya. Hal ini terjadi karena adanya pendampingan dialogis dari orang tua, yang menerapkan aturan-aturan dalam penggunaan perangkat Teknologi digital di rumah.

Studi literature review ini memberikan implikasi pada pola asuh yang dalam hal ini lebih spesifik pada kelekatan anak. Orang tua diharapkan dapat membangun kelekatan yang positif dengan anak. Kelekatan anak akan terjadi apabila orang tua banyak melakukan aktivitas bersama dengan anak. Bermain fisik secara bersama, berdialog atau berkomunikasi bersama, atau menemani anak saat menggunakan perangkat digital.

Saran bagi penelitian selanjutnya adalah memberikan pemahaman kepada orang tua terkait literasi digital untuk anak usia dini.
Pemahaman literasi digital ini dapat di bantu dengan pemberian guideline penggunaan Teknologi digital untuk anak usia din 
i.

\section{SUMBER REFERENSI}

Ansari, A., \& Crosnoe, R. (2016). Children's hyperactivity, television viewing, and the potential for child effects. Children and Youth Services Review, 61, 135-140. https://doi.org/10.1016/j.childyouth.2015.12.018

Blackwell, C. K., Lauricella, A. R., \& Wartella, E. (2014). Factors influencing digital technology use in early childhood education. Computers \& Education, 77, 82-90. https://doi.org/10.1016/j.compedu.2014.04.013

Bowlby, J. (1969). Attachment and loss: Attachment. Attachment (Vol. 1). https://doi.org/10.1177/000306518403200125

Bowlby, J. (1969). Attachment and loss Vol. 1. Attachment (Vol. 1). https://doi.org/10.1177/000306518403200125

Cain, N., \& Gradisar, M. (2010). Electronic media use and sleep in school-aged children and adolescents: A review. Sleep Medicine, 11(8), 735-742. https://doi.org/10.1016/j.sleep.2010.02.006

Chongsuvivatwong, V., Ruangdaraganon, N., Intusoma, U., Mo-suwan, L., \& Panyayong, B. (2013). Effect of television viewing on social-emotional competence of young Thai children. Infant Behavior and Development, 36(4), 679-685. https://doi.org/10.1016/j.infbeh.2013.07.001

Chusna, P. A. (2017). Pengaruh Media Teknologi digital pada Perkembangan Karakter Anak. Media Komunikasi Sosial Keagamaan, 315-330.

Ervika, E. (2005). Kelekatan (Attachment) Pada Anak. E-USU Repository Universitas Sumatera Utara, 1-17. Retrieved from http://library.usu.ac.id/download/fk/psikologi-eka ervika.pdf

Febrino. (2017). Tindakan Preventif Pengaruh Negatif Teknologi digital Terhadap Anak, 1(1), 1-21.

Goh, W. W. L., Bay, S., \& Chen, V. H. H. (2015). Young school children's use of digital devices and parental rules. Telematics and Informatics, 32(4), 787795. https://doi.org/10.1016/j.tele.2015.04.002

Hale, L., \& Guan, S. (2015). Screen time and sleep among school-aged children and adolescents: A systematic literature review. Sleep Medicine Reviews, 21, 50-58. https://doi.org/10.1016/j.smrv.2014.07.007

Hardani, R. (2017). Pengaruh Kelekatan Anak dengan Orang Tua, Guru, Teman dan Kontril Diri Terhadap Perilaku Pornografi Anak SMP. Institut Pertanian Bogor.

Holmes, J. (2014). John Bowlby and Attachment Theory. https://doi.org/10.4324/9781315879772

Ihmeideh, F., \& Alkhawaldeh, M. (2017). Teachers' and parents' perceptions of the role of technology and digital media in developing child culture in the early years. Children and Youth Services Review, 77(2016), 139-146. https://doi.org/10.1016/j.childyouth.2017.04.013

Jago, R., Stamatakis, E., Gama, A., Carvalhal, I. M., Nogueira, H., Rosado, V., \& Padez, C. (2012). Parent and child screen-viewing time and home media environment. American Journal of Preventive Medicine, 43(2), 150-158. 
https://doi.org/10.1016/j.amepre.2012.04.012

Khurana, V. G., Teo, C., Kundi, M., Hardell, L., \& Carlberg, M. (2009). Cell phones and brain tumors : a review including the long-term epidemiologic data 弥. Surgical Neurology, 72(3), 205-214. https://doi.org/10.1016/j.surneu.2009.01.019

Kildare, C. A., \& Middlemiss, W. (2017). Impact of parents mobile device use on parent-child interaction: A literature review. Computers in Human Behavior, 75, 579-593. https://doi.org/10.1016/j.chb.2017.06.003

Kirkorian, H. L., Anderson, D. R., Demers, L. B., Pempek, T. A., \& Hanson, K. G. (2010). The impact of infant-directed videos on parent-child interaction. Journal of Applied Developmental Psychology, 32(1), 10-19. https://doi.org/10.1016/j.appdev.2010.10.001

Kostyrka-Allchorne, K., Cooper, N. R., \& Simpson, A. (2017). The relationship between television exposure and children's cognition and behaviour: A systematic review. Developmental Review, 44, 19-58. https://doi.org/10.1016/j.dr.2016.12.002

Kucirkova, N., \& Zuckerman, B. (2017). A guiding framework for considering touchscreens in children under two. International Journal of Child-Computer Interaction, 12, 46-49. https://doi.org/10.1016/j.ijcci.2017.03.001

Lauricella, A. R., Wartella, E., \& Rideout, V. J. (2015). Young children's screen time: The complex role of parent and child factors. Journal of Applied Developmental Psychology, 36, 11-17. https://doi.org/10.1016/j.appdev.2014.12.001

Lavigne, H. J., Hanson, K. G., \& Anderson, D. R. (2015). The influence of television coviewing on parent language directed at toddlers. Journal of Applied Developmental Psychology, 36, 1-10. https://doi.org/10.1016/j.appdev.2014.11.004

Lin, L. Y., Cherng, R. J., Chen, Y. J., Chen, Y. J., \& Yang, H. M. (2015). Effects of television exposure on developmental skills among young children. Infant Behavior and Development, 38, 20-26. https://doi.org/10.1016/j.infbeh.2014.12.005

Linebarger, D. L., \& Vaala, S. E. (2010). Screen media and language development in infants and toddlers: An ecological perspective. Developmental Review, 30(2), 176-202. https://doi.org/10.1016/j.dr.2010.03.006

Mariskhana, K. (2017). Pengaruh Televisi dan Teknologi digital Terhadap Prestasi Belajar Anak, XV(2).

Matarma, T., Koski, P., Löyttyniemi, E., \& Lagström, H. (2016). The factors associated with toddlers' screen time change in the STEPS Study: A twoyear follow-up. Preventive Medicine, 84, 27-33. https://doi.org/10.1016/j.ypmed.2015.12.014

McDaniel, B. T., \& Coyne, S. M. (2016). Technology interference in the parenting of young children: Implications for mothers' perceptions of coparenting. Social Science Journal, 53(4), 435-443.

https://doi.org/10.1016/j.soscij.2016.04.010

Moser, A., Zimmermann, L., Dickerson, K., Grenell, A., Barr, R., \& Gerhardstein, P. (2015). They can interact, but can they learn? Toddlers' transfer learning 
from touchscreens and television. Journal of Experimental Child Psychology, 137, 137-155. https://doi.org/10.1016/j.jecp.2015.04.002

Musthafa, F. A. D. (2017). Upaya Mengatasi Kecanduan Anak Terhadap Gawai (Teknologi digital) Melalui Model Komunikasi Interaktif Orang Tua dan Anak Berdasar Al-quran, (110), 645-653.

Neumann, M. M. (2016). Young children's use of touch screen tablets for writing and reading at home: Relationships with emergent literacy. Computers and Education, 97, 61-68. https://doi.org/10.1016/j.compedu.2016.02.013

Plowman, L., Stevenson, O., Stephen, C., \& McPake, J. (2012). Preschool children's learning with technology at home. Computers and Education, 59(1), 30-37. https://doi.org/10.1016/j.compedu.2011.11.014

Repacholi, M. H. (2001). Health risks from the use of mobile phones, 120, 323331.

Riza, L. U. (2016). Perkembangan Sosial Anak Usia Dini Pengguna Teknologi digital. Psikosains, 11(2), 82-98.

Rosenqvist, J., Lahti-Nuuttila, P., Holdnack, J., Kemp, S. L., \& Laasonen, M. (2016). Relationship of TV watching, computer use, and reading to children's neurocognitive functions. Journal of Applied Developmental Psychology, 46, 11-21. https://doi.org/10.1016/j.appdev.2016.04.006

Samaha, M., \& Hawi, N. S. (2017). Associations between screen media parenting practices and children's screen time in Lebanon. Telematics and Informatics, 34(1), 351-358. https://doi.org/10.1016/j.tele.2016.06.002

Santrock, J. W. (2017). Educational Psychology. Mc Graw Hill (Vol. 91).

Sihura, F. (2018). The Role of Parents " Generation of Z " to the Early Children in the Using of Teknologi digital, 249(Secret), 55-59.

Tandon, P. S., Zhou, C., Lozano, P., \& Christakis, D. A. (2011). Preschoolers' total daily screen time at home and by type of child care. Journal of Pediatrics, 158(2), 297-300. https://doi.org/10.1016/j.jpeds.2010.08.005 